\title{
Dictionary Culture of University Students Learning English as a Foreign Language in Turkey
}

\author{
Sami Baskın ${ }^{1} \&$ Muhsin Mumcu ${ }^{2}$ \\ ${ }^{1}$ Faculty of Education, Gaziosmanpaşa University, Tokat, Turkey \\ ${ }^{2}$ School of Foreign Languages, Gaziosmanpaşa University, Tokat, Turkey \\ Correspondence: Sami Baskın, Faculty of Education, Gaziosmanpaşa University, Tokat, Turkey. Tel: \\ 90-505-325-7644. E-mail: samibaskin@gmail.com
}

\author{
Received: December 7, $2017 \quad$ Accepted: January 10, $2017 \quad$ Online Published: February 25, 2018 \\ doi:10.5539/ies.v11n3p101 \\ URL: https://doi.org/10.5539/ies.v11n3p101
}

\begin{abstract}
Dictionaries, one of the oldest tools of language education, have continued to be a part of education although information technologies and concept of education has changed over time. Until today, with the help of the developments in technology both types of dictionaries have increased, and usage areas have expanded. Therefore, it is possible to find a dictionary of different types that are applicable to each situation, rather than a single dictionary for every situation. Determining this diversity and the preferences of users is very important in terms of the quality of the education to be given and the new dictionaries to be written.

In this study, dictionary preferences of students learning English as a foreign language in Turkey, factors affecting these preferences, past dictionary experiences and trainings were discussed. For this purpose, a survey with 25 questions was collected from 83 students who were learning English in the preparatory classes of Gaziosmanpaşa University.

The data obtained from the surveys was transferred to the SPSS program and frequency analyses were made. Numerical breakdowns and descriptive analysis of students' dictionary preferences and factors affecting these preferences were realized. The results revealed that the majority of the students learning English as a foreign language in Turkey did not receive any training on using dictionaries although they bought and used their first dictionaries at primary school. It was also found that language level had an important effect on dictionary usage and as students' level of language increased they considered dictionaries as easy tools. Besides, students with lower language skills found dictionaries as more informative sources than other students.
\end{abstract}

Keywords: dictionary usage, students learning English as a foreign language in Turkey, types of dictionaries

\section{Introduction}

"The main objective of language teaching is to improve language proficiency with regard to speaking, listening, reading and writing. A variety of tools can be employed as facilitators, for instance textbooks, grammar exercises, games, role play, translation, voice recordings, video tapes, creative writing, and dictionaries" (Carstens, 1995). Dictionaries are considered to be one of the oldest and the most common among these tools and as a matter of fact they were the only source of language teaching until modern time. In modern times, along with the development of information technology and the change in the concept of education, dictionaries have performed a complementary role in supporting other course materials and learning environments, especially when it comes to the meaning of the word. In researches, all dictionary users were found to be clearly advantageous compared to those who did not use dictionaries in terms of the number of the words learned (Dakun, 2001). For this reason, the use of dictionary has become an indispensable component of home and academic life (Abecassis, 2007). Since almost everyone has a dictionary today, which implies that there are hundreds of types of dictionaries and dozens of different users, it is quite difficult to make an evaluation and comment on such a large dictionary range. Therefore, classifying them by considering their specific features will facilitate the work of researchers and users. For example, dictionaries can be classified considering the features such as density of entries, the number of languages involved, the nature of entries, axis of time, arrangement of entries, purpose, the prospective user (http://www.ciil-ebooks.net/html/lexico/link5.htm, retrieved: 01.10.2017) or can be classified as monolingual, bilingual or bilingualized considering the number of languages included and 
as native speakers and foreign language learners considering the users as Abecassis (2007) does. As this research focuses on the dictionary experiences, beliefs and assumptions of university students who learn English in Turkey, other user types have been ignored. According to Koca, Pojani, and Jashari-Cicko (2014) learners must have a wide range of vocabulary knowledge and a good lexical competence while they are learning English. Well-developed vocabulary knowledge helps learners to comprehend and communicate better and succeed in language learning process. Dictionaries are reliable references and sources for learning crucial words thus the use of dictionaries in foreign language learning has been and will continue to be an important and useful tool that provides quick and direct access to learning general and specific unknown English words. Liu (2014) considers dictionaries as the most successful and important book about language since "the explanations and illustrations provide contexts for learners of non-English natives to determine the meaning and conventional usage of words, and offer further distinction of meanings so as to tell learners how to speak and write in that language."

There is no doubt that the advantages of dictionaries are limited to these features. For instance, even though the learners attend the English classes they mostly don't have an opportunity to find their teachers outside the classroom. Yet, the students are in need of an immediate reliable source that they can consult when they encounter a range of problems concerning learning English as a second language. Quite a few researches have revealed that dictionaries can provide reliable linguistic and cultural knowledge to learners especially during self-learning process outside the classroom (Vahdany, Abdollahzade, Gholami, \& Ghanipor, 2014). Therefore, "the dictionary has been a long-time companions of many a foreign language student. It is an essential source for data concerning vocabulary items, and it is not simply a classroom tool but an object of life-long use" (Kent, 2001). The individuals who have a lifelong learning goal can reach information in all settings with the help of dictionaries. Through dictionaries, individuals have the opportunity of self-learning and developing their own language skills without any need for a teacher and they can achieve it quite easily and cheaply. When it comes to foreign language learning, dictionaries are considered to be a self-learning tool on the market that can be found and accessed easily.

\section{Purpose}

The researches on the use of the dictionary have become an important field of study since 1960 . There have been two main purposes of these researches: to produce better dictionaries and direct users to the right dictionary. The main purpose of this study is to find out students' attitudes, beliefs and assumptions about dictionaries and direct the students to the right source to improve the quality of English language learning.

\section{Method}

The data of this study were collected through a questionnaire consisting of 25 questions. 86 students participated in the questionnaire, but 83 available questionnaires were evaluated. Other surveys were eliminated because of the shortcomings they contain. The questionnaire analysis was done with SPSS programme. By looking at the frequencies of the statements in the questionnaire, the experiences, beliefs and assumptions of the students about dictionaries were interpreted.

\subsection{Subjects}

The universe of this research is university students who learn English as a foreign language in Turkey and the sample is the English Preparatory Class students at Gaziosmanpaşa University. These students are trained in five different classes and at four different levels (Beginner, Elementary, Pre-Intermediate, Intermediate). These students are placed in classes according to their level of English knowledge. The responses of 19 beginner students in optional preparatory class, 14 beginner students, 20 elementary students, 14 pre-intermediate students and 16 intermediate students were evaluated. The evaluation was based on the level of foreign language of the students. Gender, age, and other variables were not taken into consideration.

\subsection{Data Collection and Analysis}

To collect the data on dictionary cultures of students learning English as a foreign language, a previously used questionnaire for the same purpose was adapted in order to be used for Gaziosmanpaşa University. The validity and reliability of this questionnaire were tested by Barın and Gürcü and after verifying the validity and reliability; the questionnaire was used to obtain data for a master's thesis done by Gürcü (2013) and for an article written by Barın and Gür (2015). There are a total of 25 questions on this data collection tool. Some of these questions are multiple-choice and some are open-ended. The analysis of the data obtained by using this questionnaire was performed using SPSS, the frequencies were calculated and discussed by comparing them to other studies. 


\section{Findings}

The findings obtained by the questionnaire named "The culture of students' dictionary usage" are as follows:

In response to the question "When did you start to use a dictionary?", $65.1 \%$ of the students answered "at primary school". 94.7\% (18 out of 19) of the students in Optional Preparatory Beginner Class responded that they started to use a dictionary when they were "at primary school". In other groups the percentage is lower. $50 \%$ of the students in Beginner Class, $60 \%$ in Elementary Class, $57.1 \%$ in Pre-Intermediate Class and $56.2 \%$ in Intermediate Class started to use a dictionary when they were "at primary school". $88 \%$ of students learning English as a foreign language in Turkey used at least one dictionary "at secondary school". The percentage of those who had not used a dictionary until they started university education was only 6 .

To the question "When did you buy your first dictionary?", $63.9 \%$ of the students answered "at primary school". 89.5\% (17 out of 19) of the students in Optional Preparatory Beginner Class responded that first they bought a dictionary when they were "at primary school". $71.4 \%$ of the students in Beginner Class, $55 \%$ in Elementary Class, $50 \%$ in Pre-Intermediate Class and 50\% in Intermediate class bought their first dictionaries "at primary school". 90.4\% of students learning English as a foreign language in Turkey had bought a dictionary before secondary school. The percentage of those who had not bought a dictionary until they started university was only 1.2 .

As for the question "What type of dictionaries do you have?", $6 \%$ of the students answered that they had only "monolingual", 50.6\% "bilingual", $43.6 \%$ had both "monolingual and bilingual". $57.9 \%$ of the students in Optional Preparatory Beginner Class responded that they had "bilingual", $71.4 \%$ of the students in Beginner Class had both "monolingual and bilingual", $60 \%$ of the students in Elementary Class had "bilingual", $64.3 \%$ of the students in Pre-Intermediate Class had "bilingual", $43.8 \%$ of the students in Intermediate Class had "bilingual" and $43.8 \%$ of the students had both "bilingual and monolingual". $15.78 \%$ of the students in Optional Preparatory Beginner Class reported that had both "monolingual" and "bilingual", 5.26\% had "monolingual", "bilingual" and "special subject dictionaries", 5.26\% had "monolingual", "bilingual" and "encyclopaedic dictionaries", $5.26 \%$ had "monolingual", "encyclopaedic" and "special subject dictionaries". That is, $31.57 \%$ of the students in this group had more than one dictionary. 57.14\% of the students in Beginner Class answered that they had "monolingual" and "bilingual" and 7.14\% had "bilingual" and "thesaurus", $7.14 \%$ had "monolingual", bilingual", "special subject dictionaries". That is, $71.42 \%$ of the students in this group had more than one dictionary. $15 \%$ of the students in Elementary Class responded that they had "monolingual" and "bilingual", $5 \%$ "bilingual" and "encyclopaedic dictionaries" and 5\% "monolingual", "bilingual" and "encyclopaedic dictionaries". That is, $30 \%$ of the students in this group had more than one dictionary. $14.28 \%$ of the students in Pre-Intermediate Class answered that they had "bilingual" and "encyclopaedic", 7.14\% "monolingual" and "bilingual", 7.14\% "monolingual", "bilingual" and "special subject dictionaries", 7.14\% "monolingual", "bilingual" and "thesaurus". That is, $35.70 \%$ of the students in this group had more than one dictionary. $25 \%$ of the students in Intermediate Class answered that they had "monolingual" and "bilingual", $6.25 \%$ "bilingual", and "encyclopaedic dictionaries", 6.25\% "monolingual", "bilingual" and "thesaurus", 6.25\% "monolingual", "thesaurus" and "special subject dictionaries". That is, $42.75 \%$ of the students in this group had more than one dictionary.

In response to the question "Do you use online dictionaries? If your answer is yes, which ones?". $62.70 \%$ of the students answered "yes". $31.57 \%$ of the students in Optional Preparatory Beginner Class answered that they used "tureng, TDK Türkçe Sözlük, zargan, Google Translate", 50\% of the students in Beginner Class answered that they used "tureng, Google Translate, blue dictionary", $65 \%$ of the students in Elementary Class answered that they used "tureng, Google Translate, Cambridge, Oxford, zargan, sesli sözlük, english-turkish dictionary, TDK Türkçe Sözlük, vocabulary, merriam-webster”, $64.28 \%$ of the students in Pre-Intermediate Class answered that they used "tureng, dictionary.com, sesli sözlük, english-turkish dictionary", $87.5 \%$ of the students in Intermediate Class answered that they used "english-turkish dictionary, sesli sözlük, tureng, Google Translate, cambridge, oxford, longman". The students who answered "yes" stated that they used more than one online dictionary.

To the question "Do you want to buy a new dictionary?", $48.2 \%$ of the students answered that they "never" wanted to buy a new dictionary, $33.7 \%$ answered "maybe", $9.6 \%$ answered "two", $8.4 \%$ answered "more than two". 52.6\% of the students in Optional Preparatory Beginner Class answered that they "never" wanted to buy a dictionary, 21.1\% answered "one", 15.8 answered "two" and 10.5\% answered "more than two". 28.6\% of the students in Beginner Class answered that they "never" wanted to buy a new dictionary, $50.2 \%$ answered "one", $7.1 \%$ answered "two" and 14.3\% answered "more than two". $45 \%$ of the students in Elementary Class answered 
that they "never" wanted to buy a new dictionary, 30\% answered "one", 10\% answered "two" and 15\% answered "more than two". 50\% of the students in Pre-Intermediate Class answered that they "never" wanted to buy a new dictionary, 35.7\% answered "one", 14.3\% answered "two". 62.5\% of the students in Intermediate Class answered that they "never" wanted to buy a new dictionary and the rest of this class with $37.5 \%$ answered "only one".

In response to the question "Which type of dictionary do you use most frequently? $9.6 \%$ of the students answered that they used "monolingual", $85.5 \%$ answered "bilingual", 2.4\% answered "thesaurus" and $2.4 \%$ answered "encyclopaedic". 15.8\% of the students in Optional Preparatory Beginner Class answered that they used "monolingual", 84.2\% "bilingual". 92.9\% of the students in Beginner Class answered that they used "bilingual", 7.1\% "thesaurus". 5\% of the students in Elementary Class answered that they used "monolingual", 90\% "bilingual" and 5\% "thesaurus". 7.1\% of the students in Pre-Intermediate Class answered that they used "monolingual", 78.6\% "bilingual" and 14.3\% "encyclopaedic". 18.8\% of the students in Intermediate Class answered that they used "monolingual", 68.8\% "bilingual" and $12.4 \%$ "thesaurus".

As for the question "In your opinion what type of dictionary is the most useful?", $12 \%$ of the students answered "monolingual", 65.1\% answered "bilingual", 12\% answered "thesaurus", 8.4\% answered "encyclopaedic" and 2.4\% answered "special subject dictionaries". 89.5\% of the students in Optional Preparatory Beginner Class responded that they found "bilingual dictionaries" more useful than the other dictionary types, 5.3\% of the students found "encyclopaedic" and 5.3\% of the students found "special subject dictionaries" more useful that the other dictionary types. $92.9 \%$ of the students in Beginner Class found "bilingual" and $7.1 \%$ of the students found "thesaurus" as the most useful dictionaries. 15\% of the students in Elementary Class found "monolingual", 40\% "bilingual", 25\% "thesaurus" and 20\% "encyclopaedic" as the most useful sources. 21.4\% of the students in Pre-Intermediate Class found "monolingual dictionaries" 42.9\% "bilingual", $21.4 \%$ "thesaurus" and $14.3 \%$ "encyclopaedic" as the most useful sources. $25 \%$ of the students in Intermediate Class found "monolingual", $62.5 \%$ "bilingual", $6.2 \%$ "thesaurus" and 6.2\% "special subject dictionaries" as the most useful dictionary types.

In response to the question "Why did you buy the most recent dictionary you own?" $62.2 \%$ of the students responded "because a teacher recommended it", the rest of the students with $39.8 \%$ responded "as a result of my own choice". When the question was examined according to language levels, $73 \%$ of the students in Optional Preparatory Beginner Class, $85.7 \%$ of the students in Beginner Class, 50\% of the students in Elementary Class, $35.7 \%$ of the students in Pre-Intermediate Class and $56.2 \%$ of the students in Intermediate Class responded that they bought a dictionary "because a teacher recommended it".

To the question "What are your priorities when buying a dictionary?", $37.3 \%$ of the students answered only one priority. $27.7 \%$ of the students answered "relevance to my needs", $6 \%$ "number of words", $2.4 \%$ "number of examples", $1.2 \%$ "the reputation of the publisher". $62.7 \%$ of the students selected more than one option. When this group of students with $62.7 \%$ was examined, it was found that students' priorities were "relevance to my needs", "reasonable price" and "ease of transport". Since the students thought the number of words in the dictionary as a need, the number of students who both selected the "number of words" and "relevance to my needs" was quite high. $47.4 \%$ of the students in Optional Preparatory Beginner Class, 57.1\% in Beginner Class, $55 \%$ in Elementary Class, $71.4 \%$ in Pre-Intermediate Class and $87.5 \%$ in Intermediate Class answered both "relevance to my needs" and "number of words".

As for the question "What do you remember about your favourite dictionary?", $7.2 \%$ of the students answered "title", 3.6\% "colour", 4.8\% "publisher", 4.8\% "size", 7.2\% "number of words", 1.2\% "pictures" and 2.4\% "number of languages". In addition, $68.7 \%$ of the students selected more than one option. When this group of students with $68.7 \%$ was examined, it was seen that $42.10 \%$ of the students in Optional Preparatory Beginner Class selected "title" along with another option, 26.31\% selected "number of words", "colour" or size" along with another option. $57.14 \%$ of the students in Beginner Class selected "colour" or "title "along with another option, 35.7\% selected "size "along with another option. 40\% of the students in Elementary Class selected "colour" along with another option, 35\% selected "number of languages" along with another option, 30\% selected "title" or "number of words" along with another option, 20\% selected "publisher" along with another option. 57.14\% of the students in Pre-Intermediate Class selected "colour" along with another option, 42.85\% "title" along with another option, 35.71\% "publisher" along with another option, 28.57\% "size" along with another option. $68.75 \%$ of the students in Intermediate Class selected "title" or "colour" along with another option, $31.25 \%$ selected "publisher ", and 25\% selected "size" of the dictionary.

In response to the question "Do you ever use the information contained in the appendices?", 56.6\% of the students answered "yes" and $43.4 \%$ of the students answered "no". When the question was examined according 
to language levels, it was found that $47.4 \%$ of the students in Optional Preparatory Beginner Class, $64.3 \%$ of the students in Beginner Class, $55 \%$ of the students in Elementary Class, $64.3 \%$ of the students in Pre-Intermediate Class and $56.2 \%$ of the students in Intermediate Class consulted the information contained in the appendices at least once.

For the question "If your answer is yes which kind(s) of information do you use?", $9.6 \%$ of the students answered "list of abbreviations", $8.4 \%$ "grammar", $1.2 \%$ "names of cities, districts and plate numbers" and $80.8 \%$ of the students selected more than one option. When this group of students with $80.8 \%$ was examined, it was found that $55.55 \%$ of the students in Optional Preparatory Beginner Class selected "list of abbreviations" along with another option, 44.44\% "grammar" along with another option" and 33.33\% "proper names" along with another option. $77.77 \%$ of the students in Beginner Class selected "list of abbreviations" along with another option, 66.66\% "grammar" along with another option and 33.33\% "proper names" along with another option. $45.45 \%$ of the students in Elementary Class selected "proper names" along with another option and 36.36\% "list of abbreviations" along with another option. 55.55\% of the students in Pre-Intermediate Class selected "grammar" along with another option and $44.44 \%$ "list of abbreviations" along with another option. 33.33\% of the students in Intermediate Class selected "list of abbreviations" along with another option and 22.22\% "grammar" along with another option.

In response to the question "Have you ever read front-matter guidance notes in order to know how to use your dictionary?", $28.9 \%$ of the students answered "yes" and 71.1\% of the students answered "no". Since no significant difference was found between the percentages of the groups, further analysis between the groups was not preferred to discuss.

As for the question "When do you use a dictionary?", $7.2 \%$ of the students answered only "in the classroom", $31.3 \%$ only "studying at home", $1.2 \%$ only "studying at the library". $60.2 \%$ of the students selected more than one option and When this group of students with $60.2 \%$ was examined, it was found that $40 \%$ of the students in Optional Preparatory Beginner Class selected "at home" and "in the classroom", $40 \%$ selected "at home", "in the classroom" and "at the library", $10 \%$ selected "in the exam" and "in the classroom", $10 \%$ selected "in the classroom," in the exam" and "at home". $72.72 \%$ of the students in Beginner Class selected "in the classroom" and "at home", 27.28\% selected "at home", "at school" and "at the library". $66.66 \%$ of the students in Elementary Class selected "in the classroom" and "at home", $22.22 \%$ selected "in the classroom", "at home" and "at the library", $11.12 \%$ selected "at home" and "at the library". $22.22 \%$ of the students in Pre-Intermediate Class selected "at home" and "at the library", 33.33\% selected "in the classroom" and "at home", $44.45 \%$ selected "in the classroom", "at home" and "at the library". 54.55\% of the students in Intermediate Class selected "at home" and "in the classroom", 27.27\% selected "at home" and "at the library", 18.18\% selected "at home", "in the classroom" and "at the library".

In response to the question "Do you use a dictionary while you are...?", $4.8 \%$ of the students answered "reading of textbooks or academic journals", 2.4\% "writing", 4.8\% "playing word games", $1.2 \%$ "when we have something on our minds while having conversation with friends" "and 7.2\% "translating". $78.3 \%$ of the students selected more than one option. When this group of students with $78.3 \%$ was examined, it was found that $83.33 \%$ of the students in Optional Preparatory Class selected "translating", 66.66\% "writing", 50\% "reading of textbooks and academic journals", 41.66 "searching for something as a hobby" and "when we have something on our minds while having conversation with friends". $92.30 \%$ of Beginner Class students selected "reading of textbooks and academic journals", $84.61 \%$ "writing", $84.61 \%$ "translating", $46.15 \%$ "searching for something as a hobby" and 23,07\% "playing word games". $76.92 \%$ of the students in Elementary Class selected "translating", $38.46 \%$ "writing", $38.46 \%$ "reading of textbooks and academic journals", 30.76\% "when we have something on our minds while having conversation with friends", $23,07 \%$ "searching for something as a hobby". $84.61 \%$ of the students in Pre-Intermediate Class selected "translating", 76.92\% "writing", 61.53\% "reading of textbooks and academic journals", $30.76 \%$ "searching for something as a hobby", $23,07 \%$ "when we have something on our minds while having conversation with friends". $92.85 \%$ of the students in Intermediate Class selected "translating", 57.14\% "reading of textbooks and academic journals", 57.14\% "writing", 35.71\% "when we have something on our minds while having conversation with friends", $28.57 \%$ "searching for something as a hobby".

In response to the question "What do you do when you encounter a new or difficult word while reading?", $10.8 \%$ of the students responded "try to guess the meaning", 3.6\% "ask other people what it means", $28.9 \%$ "look it up in a dictionary", $43.4 \%$ "first try to guess the meaning and then look it up in a dictionary", $13.3 \%$ "try to find a solution according to the situation". When the answers were examined according to language levels, $10.5 \%$ of the students in Optional Preparatory Beginner Class answered that they "try to guess the meaning", $10.5 \%$ "ask other people what it means", $26.3 \%$ "look it up in a dictionary", $36.8 \%$ "first try to guess the meaning and then 
look it up in a dictionary", $15.8 \%$ "try to find a solution according to the situation". $42.9 \%$ of the students in Beginner Class answered that they "look it up in a dictionary", $42.9 \%$ "first guess the meaning and then look it up in a dictionary", $14.3 \%$ "try to find a solution according to the situation". $15 \%$ of the students in Elementary Class answered that they "try to guess the meaning", $5 \%$ "ask other people what it means", $25 \%$ "look it up in a dictionary", $40 \%$ "first guess the meaning and then look it up in a dictionary", $15 \%$ "try to find a solution according to the situation". $7.1 \%$ of the students in Pre-Intermediate Class answered that they "try to guess the meaning", $28.6 \%$ "look it up in a dictionary", $50 \%$ "first guess the meaning and then look it up in a dictionary", $14.3 \%$ "try to find a solution according to the situation". $18.8 \%$ of the students in Intermediate Class answered that they "try to guess the meaning", $25 \%$ "look it up in a dictionary", $50 \%$ "first guess the meaning and then look it up in a dictionary", 9.1\% "try to find a solution according to the situation".

To the question "Why do you refer to a dictionary", $18.1 \%$ of the students answered "to find meaning", $1.2 \%$ "to find spelling" and $80.7 \%$ of the students selected more than one option. When this group of students with $80.7 \%$ was examined, $100 \%$ of the students in Optional Preparatory Beginner Class answered that they consulted dictionaries "to find meaning", $86.66 \%$ "to find spelling", 46.66\% "to find pronunciation", $40 \%$ "to find examples of use". $100 \%$ of the students in Beginner Class answered that they consulted dictionaries "to find meaning", $75 \%$ "to find spelling", $75 \%$ "to find pronunciation", $50 \%$ "to find examples of use", $16.66 \%$ "to check grammar". $93.75 \%$ of the students in Elementary Class answered that they consulted dictionaries "to find meaning", $68.75 \%$ "to find spelling", $37.5 \%$ "to find pronunciation", $37.5 \%$ "to find examples of use", $6.25 \%$ "to check grammar", $6.25 \%$ " to find word origin", $6.25 \%$ "to find synonyms". $100 \%$ of the students in Pre-Intermediate Class answered that they consulted dictionaries "to find meaning", $69.23 \%$ "to find pronunciation", $69.23 \%$ "to find examples of use", $61.53 \%$ "to find spelling", $38.46 \%$ "to find synonyms", $7.69 \%$ " to find word origin". $100 \%$ of the students in Intermediate Class answered that they consulted dictionaries "to find meaning", $50 \%$ "to find pronunciation", $50 \%$ "to find examples of use", $41.66 \%$ "to find spelling", $41.66 \%$ "to find synonyms", $8.33 \%$ "to find grammatical points".

As for the question "Do you have a dictionary application on your mobile phone? If your answer is yes what applications do you use?", $69.9 \%$ of the students responded "yes", $30.1 \%$ of the students responded "no". $31.6 \%$ of the students in Optional Preparatory Beginner Class, $50 \%$ of the students in Beginner Class, $80 \%$ of the students in Elementary Class, $100 \%$ of the students in Pre-Intermediate Class, $93 \%$ of the students in Intermediate Class used at least one dictionary application on their mobile phones. The applications that were downloaded to their mobile phones according to language levels of students were:

Students in Optional Preparatory Beginner Class: Tureng and TDK Turkish Dictionary,

Students in Beginner Class: TR-ENG Translator, English-Turkish Dictionary, Blue Dictionary, Tureng, Google Translate,

Students in Elementary Class: Tureng, Google Translate, Oxford Dictionary, Sesli Sözlük, English-Turkish Dictionary, TR-ENG Translator,

Students in Pre-Intermediate Class: Tureng, Oxford Dictionary, Sesli Sözlük, English-Turkish Dictionary, bravolol, AA Dictionary,

Students in Intermediate Class: Sesli Sözlük, Engilish-Turkish Dictionary, Tahir Hoca İngilizce Sözlük, Tureng, Oxford Dictionary, AA Dictionary, Cambridge Dictionary

In response to the question "Does it happen that you cannot find the information you look for in the dictionary?", $13.3 \%$ of the students responded "never" and $86.7 \%$ of the students responded "sometimes". When the answers were examined according to language levels, $89.5 \%$ of the students in Optional Preparatory Beginner Class, $64.3 \%$ of the students in Beginner Class, $95 \%$ of the students in Elementary Class, $78.6 \%$ of the students in Pre-Intermediate Class and $100 \%$ of the students in Intermediate Class stated that they "sometimes" could not find the information they looked for in the dictionary.

As for the question "Which type of information is the most difficult to find?", $10.8 \%$ answered "specialized technical terms", 16.9\% "idioms and phrases", 8.4\% "Turkish words in a special subject area", 1.2\% "common Turkish words", $6 \%$ "examples of use", $4.8 \%$ "grammar labels" and $51.8 \%$ selected more than one option. When this group of students with $51.8 \%$ was examined, it was found that $88.88 \%$ of the students in Optional Preparatory Beginner Class stated that they had difficulty in finding "idioms", 66.66\% "grammar labels", $55.55 \%$ "Turkish words in a special subject area". $71.42 \%$ of the students in Beginner Class stated that they had difficulty in finding "idioms", 42.85\% "grammar labels", 28.57\% "examples of use", $28.57 \%$ "specialized technical terms", $28.57 \%$ "Turkish words in a special subject area". $100 \%$ of the students in Elementary Class 
stated that they had difficulty in finding "idioms", $66.66 \%$ "specialized technical terms", $22.22 \%$ "examples of use". $80 \%$ of the students in Pre-Intermediate Class stated that they had difficulty in finding "idioms", $60 \%$ "specialized technical terms", 50\% "grammar labels", 30\% "Turkish words in a special subject area". $88.88 \%$ of the students in Pre-Intermediate Class stated that they had difficulty in finding "idioms", $77.77 \%$ "specialized technical terms", 44.44\% "Turkish words in a special subject area", $22.22 \%$ "grammar labels".

To the question "What do you think about the causes of these difficulties?", $8.4 \%$ of the students responded "my lack of dictionary skill", $22.9 \%$ "my lack of dictionary knowledge", $26.5 \%$ "not enough knowledge in the dictionary", 3.6\% "unclear layout of the dictionary", 1.2\% "I don't read the instruction to the user", 34.9 selected more than one option, 2.4\% had no idea. As the causes of the difficulties, $26.3 \%$ of the students in Optional Preparatory Beginner Class answered "my lack of dictionary knowledge", $35.7 \%$ of the students in Beginner Class selected more than one option, 35\% of the students in Elementary Class answered "not enough knowledge in the dictionary", $50 \%$ of the students in Pre-Intermediate Class selected more than one option, $31.2 \%$ of the students in Intermediate Class answered "not enough knowledge in the dictionary".

In response to the question "Using dictionaries is.....", 44.6\% of the students answered "worthwhile/ informative", $2.4 \%$ "easy", 3.6\% exciting/fun, $8.4 \%$ "tedious/boring", $1.2 \%$ "of little help, $38.6 \%$ of the students selected more than one option, $1.2 \%$ had no idea. $63.2 \%$ of the students in Optional Preparatory Beginner Class, $57.1 \%$ of the students in Beginner Class, $35 \%$ of the students in Elementary Class, $28.6 \%$ of the students in Pre-Intermediate Class, $28, \%$ of the students in Intermediate Class answered that they found dictionaries as "worthwhile/informative". While none of the students in Optional Preparatory Beginner Class and Beginner Class considered dictionaries as easy tools, $5 \%$ of the students in Elementary Class, $7.1 \%$ of the students in Pre-Intermediate Class and $8 \%$ of the students in Intermediate Class considered dictionaries as easy.

As for the question "Using dictionaries can...", 3.6\% of the students answered "improve my writing", $27.7 \%$ "help me perform better in my studies", $2.4 \%$ "improve my speaking", $4.8 \%$ "of no use", $61.4 \%$ of the students selected more than one option. When the answers were examined according to language levels, $10.5 \%$ of the students in Optional Preparatory Beginner Class answered "improve my writing", $21.1 \%$ "help me perform better in my studies", $5.3 \%$ "of no use" and $63.2 \%$ considered that dictionaries had more than one advantage. $35.7 \%$ of the students in Beginner Class answered "help me perform better in my studies", $7.1 \%$ "of no use", $57.1 \%$ considered that dictionaries had more than one advantage. $25 \%$ of the students in Elementary Class answered "help me perform better in my studies", 10\% "improve my speaking", $10 \%$ "of no use", 55\% considered that dictionaries had more than one advantage. $7.1 \%$ of the students in Pre-Intermediate Class answered "improve my writing", $14.3 \%$ "help me perform better in my studies", $78.6 \%$ considered that dictionaries had more than one advantage. $43.8 \%$ of the students in Intermediate Class answered "help me perform better in my studies", $56.2 \%$ considered that dictionaries had more than one advantage.

In response to the question "What do you think that the following abbreviations refer to?, none of the students could exactly give the right answers to any of the questions. The question included 13 abbreviations such as $n s z$ (nesnesiz), -i. (), s. (), öz. (), ç. (), zf. (zarf), e. (edat), zm. (zamir), -den (), yar. (), den. (), -e. (), mec. (). 39.8\% of the students did not answer this question. $7.2 \%$ of the students answered the question but all the answers were incorrect. $53 \%$ of the students only answered some of the questions correctly. $59 \%$ of the students who answered the question gave the correct answer for "zm.", $47 \%$ for "e.", $45 \%$ for "öz.", $37.7 \%$ for "mec. and $25.5 \%$ for "yar.".

To the question "Have you ever been taught how to use a dictionary?", 26.5\% of the students answered "yes", $39.8 \%$ of the students answered "a little "and $33.7 \%$ of the students answered "never". This result indicated that three fourth of the students did not have enough training on dictionaries.

\section{Results and Discussion}

Jackson (2002) highlights the importance of dictionaries as follows "every household is assumed to have one; children are taught how to consult the dictionary in school; there is one in every office. Lawyers quote the dictionary in court, teachers and lecturers appeal to it, politicians and preachers argue from its definitions". He further states that even though all the dictionaries are thought to be similar since all of them give definitions of the words which are listed alphabetically, in fact they have different formats, highly variable numbers of pages and a variety of page layouts (Jackson, 2001). In this case, which dictionary types do the learners who learn a new language use? Why do the learners need to use a dictionary and in what circumstances do they consult a dictionary? In fact, these questions have been the common starting point of researches on dictionary use in the last thirty years. According to Nuccorini (1992) one of the main subjects for a lot of different studies on lexicography in the last thirty years has been the dictionary use. The subjects of these studies have been mainly 
students, teachers, translators and foreign language learners in general. Researchers have investigated primarily English language along with French and German and studied dictionaries for native speakers, for foreign learners, or for both, and with mono- and bilingual dictionaries.

In Turkey, some studies (Barın \& Gür, 2015; Şevik, 2017) were carried out with groups learning English as a foreign language. This research was based on Barın and Gür's (2015) study. It was aimed to check whether the behaviour of groups in similar situations coincides or not. In addition, responses to similar questions in other studies were compared and evaluated. The results and evaluations are as follows:

The first dictionary experience of $65.1 \%$ of the students learning English as a foreign language in Turkey was realized when they were at primary school. $88 \%$ of the students had used a dictionary when they were at secondary school. Only $6 \%$ of the students had not used a dictionary until they started university. Similar results were obtained in Barın and Gür's (2015) study where it was stated that $56.3 \%$ of the students started to use a dictionary when they were at primary school and $28.5 \%$ of the students at secondary school.

In Turkey $63.9 \%$ of the students learning English as a foreign language bought their first dictionary when they were at primary school. When the students were at secondary school the percentage reached to $90.4 \%$. The percentage of the students who did not buy a dictionary until they started university was only 1.2 . According to Barın and Gür's (2015) study, 51.7\% of the students bought their first dictionary when they were at primary school and $78.2 \%$ of the students had a dictionary at secondary school. When two studies compared, it can be seen that the years between two studies had a positive effect on the percentage of buying a dictionary. According to a survey on Japanese students learning English, $88.6 \%$ of Japanese students got their first dictionaries in junior high school, $11.4 \%$ in high school and $0 \%$ at university (Baxter, 1980). Therefore, it can be concluded that although Japanese students started buying dictionaries later than Turkish students, they completed dictionary buying process in a shorter time than Turkish students.

$6 \%$ of the students learning English as a foreign language stated that they had only "monolingual", $50.6 \%$ "bilingual", 43.4\% both "monolingual and bilingual dictionaries". In Barın and Gür's (2015) study it was found that $78.1 \%$ of the students had "bilingual" and $74.2 \%$ had "monolingual". This result indicated that quite a few students had more than one dictionary. According to a research on Korean students learning English as a foreign language at intermediate level, it was found that all the students had at least one dictionary, some of the students had two or four different dictionaries. $96 \%$ of the students had bilingual, $2 \%$ had monolingual (English-English) and 2\% had English-English-Korean dictionary (Kent, 2001). It can be reasonably concluded that Korean EFL students prefer bilingual dictionaries more than Turkish students.

The percentage of Turkish EFL students who stated that they used online dictionaries was $62.70 \%$. It was found that the students who used online dictionaries used more than one online dictionary. As language skills of students improved, English-origin dictionaries (Cambridge, Oxford, Longman, etc.) were more commonly used. In the same way, parallel to the development of language skills the use of programs such as Google Translate, which translates sentences, decreased. As language level increased, the percentage of online dictionary usage increased. $87.5 \%$ of the students studying in Intermediate class used online dictionary. Online dictionary users consulted multiple sources to confirm the correctness of the information. In Barın and Gür's (2015) study it was found that only $41.1 \%$ of the students used online dictionaries. This increase in the use of online dictionaries can be attributed to information technologies that have developed and to the internet service that has become cheaper in recent years.

The finding of the study revealed that the most advanced group in terms of language level had more dictionaries than the other groups. $42.75 \%$ of the students in this group had more than one dictionary. This result can be explained by the results of the research of Sayed and Siddiek (2015). According to Sayed and Siddiek's (2015) research, Sudanese EFL students with low language skills believed that having many dictionaries did not contribute much to language learning. Turkish students with low language skills were likely to share the same idea with Sudanese students. As a result, students with low language skills also had fewer dictionaries than the students with higher language skills. According to Barın and Gür's (2015), 94.2\% of EFL students in Turkey had more than one dictionary.

As students' level of language increased, the desire to acquire a new dictionary decreased. While only $28.22 \%$ of the students in Beginner Class did not think of buying a new dictionary, $45 \%$ of the students in Elementary class, $50 \%$ in Pre-Intermediate Class and $62.5 \%$ in Elementary Class did not think of buying a new dictionary. According to a study on dictionary culture of first-class EFL students in Algeria, only $34 \%$ stated that "they will get a new dictionary soon" (Hamdi, 2014). This finding was in contrast to the finding of Beginner Class students in Turkey. It was surprising that these two groups, which had similar language levels, were not similar in their 
desire to buy a dictionary, and this could be seen as a divergence of dictionary cultures of two countries. The fact that EFL students in Turkey who had lower level of language had a higher desire to get a new dictionary could be explained with the fact that students with lower level of language had fewer dictionaries than the other groups.

As the level of language increased there was an increase in the use of monolingual dictionaries, Beginner with $0 \%$, Elementary with 5\%, Pre-Intermediate with $7.1 \%$ and Intermediate with $18.8 \%$ and a decrease in the use of bilingual dictionaries, Beginner Class with $92.9 \%$, Elementary Class with 90\%, Pre-Intermediate Class with $78.6 \%$ and Intermediate Class with $68.8 \%$. This result could be supported by dictionary preferences of students learning English. Similar behaviour was observed in Albanian students with advanced language level. Most of the Albanian students with advanced language level (80\%9) had monolingual dictionaries and $72.5 \%$ of the students preferred to use monolingual dictionaries (Koca et al., 2014). Similarly, the preference of Sudanese EFL students was monolingual dictionaries. According to $77 \%$ of Sudanese EFL students, monolingual dictionaries were better than bilingual ones. $69 \%$ of the students also did not believe that in some respects, bilingual dictionaries were better than monolingual dictionaries (Sayed \& Siddiek, 2015). Therefore, Sudanese EFL students preferred monolingual dictionaries. In Barın and Gür's (2015) study, 57.6\% of EFL students preferred bilingual and $34.4 \%$ preferred monolingual dictionaries.

As the level of language increased, students considered monolingual dictionaries as more useful tools and the percentage of the acceptance increased. $15 \%$ of the students in Elementary Class students, $21.4 \%$ in Pre-Intermediate Class and $25 \%$ of the students in Intermediate Class found monolingual dictionaries more useful than the other types, while nobody at Beginner level found monolingual dictionaries useful.

As students' language level increased, there was an increase in behaviour to act independently and to find and purchase the dictionary as a result of their own choices. While a large amount of students at Beginner level acted in accordance with teacher's recommendation, in the behaviour of groups with more advanced language level, students' own choices were as influential as the teacher's recommendation. In Barın and Gür's (2015) study, $51 \%$ of the students bought dictionaries as a result of teachers' recommendation and $41.7 \%$ of the students acted independently and bought their dictionaries as a result of their own deliberate choices. When the findings in Barın and Gür's (2015) study was compared to the findings in Koca et al.'s (2014) study on Albanian students, similar results were obtained. $60 \%$ of Albanian students bought dictionaries as a result of teachers' recommendation (Koca et al., 2014). However, according to a research on Korean EFL students at intermediate level, it was found that $58 \%$ of the students chose their dictionaries as a result of their own choices. This indicated that students evaluated various types of dictionaries and chose a dictionary type that could meet their needs in their own work. The dictionaries of the rest of the students with $42 \%$ were chosen by a family member (Kent, 2001). The findings of the research on Korean EFL students supported the findings in this study. As students' level of language increased, the behaviour of acting independently in dictionary selection and of determining their own dictionaries increased as well.

Students preferred more comprehensive dictionaries when their level of language increased. Students believed that their needs could only be met by more comprehensive dictionaries as they became more competent in language. Therefore, $47.4 \%$ of the students in Optional Preparatory Class, $57.1 \%$ of the students in Beginner Class, $55 \%$ of the students in Elementary Class, $71.4 \%$ of the students in Pre-Intermediate Class and $87.5 \%$ of the students in Intermediate Class answered that they took into consideration both their needs and the number of the words when they bought a dictionary. In Barın and Gür's (2015) study, when students bought a dictionary, $74.8 \%$ of them took their needs into consideration, $53 \%$ number of words and $32.5 \%$ number of examples. Taking all the findings into consideration, it can be concluded that dictionary selection behaviours of Turkish EFL students and Sudanese EFL students were similar since the needs of the users and the number of the words in a dictionary were the two most important factors when selecting a dictionary (Sayed \& Siddiek, 2015). In a detailed research with more than 1.100 students from seven countries on the use of dictionaries by students of English as a foreign language, native speakers of French, German, Italian and Spanish, students were asked to select the factors influencing their choice of first dictionary and it was found that $50.8 \%$ of the students bought their first dictionary as a result of "teacher's recommendation", 11.2\% "bookseller's recommendation, 7.1\% "parents' recommendation", $6.1 \%$ "friend's recommendation", $4.5 \%$ "low price", $9.5 \%$ "clear presentation", $.9 \%$, "good illustrations" and 13.6\% "it was a gift" (Atkins \& Knowles: 1990).

It was observed that the students learning English as a foreign language in Turkey remembered mostly the physical characteristics such as colour, size and name of the dictionaries they had in the past. The information about the content of the dictionary was not remembered much. Similar results were obtained in Barın and Gür's (2015) study. According to their study, the four most remembered items were colour, title/name of the dictionary, 
number of words and size. Sudanese EFL students also remembered similar items. However, they mostly remembered the name of their dictionaries with $83 \%$ (Sayed \& Siddiek, 2015).

On an average, half of EFL students in Turkey consulted the information contained in the appendices. On the other hand, it can be reasonably concluded that half of the students did not consult the information contained in the appendices. A different result was found in Barın and Gür's (2015) study. According to the results of their research, $82.8 \%$ of the students referred to the information contained in the appendices. $34 \%$ of Algerian EFL students (Hamdi, 2014) and 14\% of Sudanese EFL students (Sayed \& Siddiek, 2015) were interested in appendices part of the dictionary.

When EFL students in Turkey consulted the information contained in the appendices, they generally consulted abbreviations, grammatical points, proper names, city and district names and their plate numbers. In Barın and Gür's (2015) study it was seen that students consulted appendices to check irregular verbs, abbreviations and proper names. $64.7 \%$ of Algerian EFL students consulted appendices to check" irregular verbs", 47,05\%" abbreviations", 41.17\%" pronunciation and spelling" and 23.52\% "grammatical points" (Hamdi, 2014).

Students learning English as a foreign language did not often read the front-matter guidance notes, only one fourth of the students read the notes in front-matter. This behaviour coincided with Algerian and Sudanese students' behaviours who did not read the front-matter guidance notes. The percentage of the Sudanese EFL students who read the front-matter guidance notes was only 7 (Sayed \& Siddiek, 2015) and only 18\% of Algerian students read the front-matter guidance notes (Hamdi, 2014). In Barın and Gür's (2015) study it was found that $54.3 \%$ of the students read this part of dictionaries.

Students learning English as a foreign language generally consulted dictionaries when they were studying individually therefore they mostly used dictionaries at home and at the library. The usage of dictionaries in the classroom was also frequent. According to Barın and Gür's (2015) study, the dictionary was mostly used at home, in the exam, in the classroom and in the library. Similarly, according to a recent survey about the dictionary behaviours of Turkish students, printed and computer based dictionaries were mostly preferred at home with 80.11\% (Şevik, 2017). Actually, similar results were obtained in different countries. For example, the findings of a study on Albanian EFL students revealed that students mostly used their dictionaries at home, only half of the students used their dictionaries at school. The main reason of this result was that they got the necessary information they sought from their English language teachers in their English classes (Koca, et al., 2001). Similarly, Korean EFL students mostly (63\%) used their dictionaries at home (Kent, 2001).

Most of the students learning English as a foreign language consulted dictionaries in more than one case, respectively these were: while translating, reading something, writing something, when we have something on our minds while having conversation with friends and searching something as a hobby. Beginner students mostly used dictionaries while reading $(92.30 \%)$. However, as the vocabulary knowledge of students increased, reading was replaced by translation. $76.92 \%$ of the students in Elementary Class, $84.61 \%$ of the students in Pre-Intermediate Class and $92.85 \%$ of the students in Intermediate Class consulted dictionaries while translating. In Barın and Gür's (2015) study, students most frequently with 94\% used dictionaries when they were translating, and respectively it was followed by writing with $73.5 \%$, reading textbooks and academic journals with $67.5 \%$, reading for fun with $23.8 \%$. A large amount of Albanian EFL students used dictionaries for reading activities with $95 \%$, and respectively for translating with 92.5 , writing with $82 \%$, listening with $37.5 \%$ and speaking activities with $20 \%$ (Koca et al., 2014). The percentage of using dictionaries in reading actives of Sudanese EFL students was $83 \%$ (Sayed \& Siddiek, 2015). While Sudanese and Turkish EFL students showed similar attitudes in using dictionary, they showed different attitudes in writing and translating. In these activities Sudanese EFL students consulted dictionaries less than Turkish EFL students did. Therefore, it could be concluded that Turkish and Albanian EFL students showed similar attitudes in using dictionary. As to the Korean EFL students, the percentage of using dictionaries while reading is 69 and writing is 18 (Kent, 2001).

As EFL students' language levels and vocabulary knowledge increased, it was observed that when the students had a problem with a word they tended to use mental process first, to try to infer the meaning later and to verify the meaning of the word from dictionary. This result coincided with Knight's study. According to Knight's study, many students with high verbal ability referred to the dictionary when they had already correctly guessed the meaning (Knight, 1994). In their study, Barın and Gür (2015) ignored the level of language. They found that when students had a problem with a word, they looked it up in the dictionary first (58.3\%). Yet, a significant number of the students with $31.8 \%$ tried to infer the meaning without the help of the dictionary, which made about one third of the students Barın and Gür (2015). Although many researchers, teachers and textbook writers have encouraged students to infer the meaning first (Xu, 2010), students who used dictionaries learned more 
words and showed higher reading comprehension achievement compared to the students who inferred meaning from the context (Knight, 1994).

EFL students used dictionaries mostly to find the meaning of words. Respectively it was followed by spelling, pronunciation, and examples of usage. It was seen that as the language level of students increased, they tended to look at more specific points such as grammatical labels and etymology of the words. Similar results were obtained in Barın and Gür's (2015) study. According to the study, $94.7 \%$ of the students looked up a word in dictionary to find the meaning, $64.2 \%$ to find examples of usage, $50.3 \%$ to find pronunciation and $37.7 \%$ to find synonyms. In Şevik's (2017) research, 96\% of the subjects mostly looked up a word in a dictionary to find meaning, $92 \%$ to check the meaning of the word, $75 \%$ to check spelling, $73 \%$ to learn spelling, $62 \%$ to learn pronunciation, $56 \%$ to check pronunciation. These findings were similar to those about EFL students around the world. For instance, in their studies on Iranian EFL students Vahdany et al. (2014) and on Sudanese EFL students Sayed and Siddiek (2015) found that students mostly consulted dictionaries to find the meaning/look up the definition of the word and the translation equivalent in target language. These results coincide with the results obtained from the studies which have been done on the dictionary usage with different groups in the last thirty years. According to recent studies, students have consulted dictionaries mostly to find the meaning of the words (Nuccorin, 1992).

As the language skills of EFL students developed and students learned how to use a dictionary, they tended to use online dictionaries such as mobile phone applications. It was observed that students with higher language skills used more applications and websites. In addition, students with higher level of language used applications based on vocabulary translation instead of application based on sentence translation such as Google translate etc. While quite a few of Beginner and Elementary students had applications like Google Translate, only one students in Pre-Intermediate and Intermediate Class downloaded such applications. According to the study on advanced level of EFL students in Turkey, students had paper dictionaries at most with $96.77 \%$ and the second most common used dictionary type with $85.48 \%$ was mobile phone dictionaries. $10 \%$ of the subjects had monolingual, $25 \%$ bilingual, $51 \%$ both monolingual and bilingual dictionaries. In addition, $29 \%$ of the subjects had online mobile phone dictionaries, $37 \%$ downloaded phone dictionary and $18 \%$ both online and some other applications. $62 \%$ of the subjects responded to the question of their favourite website or application. $37 \%$ of the subjects who responded to this question stated "tureng.com", 15\% "zargan.com" and 14\% translate.google.com".

The most difficult type of information for EFL students to find was idioms. They were followed by specialized technical terms, words in a special subject area, examples of usage, grammar labels. In their study, Barın and Gür (2015) reported specialized technical terms with $71.5 \%$, idioms and phrases with $55.6 \%$, common words in a special subject area with $22.5 \%$ as the most difficult type of information to find. In a study on dictionary culture of Algerian freshman students, $42 \%$ of the students stated that "the definitions are not clear enough", $40 \%$ the word does not exist in the dictionary, $24 \%$ could not find the information, $12 \%$ have problems in finding the information, $8 \%$ the examples of usage are of little help (Hamdi, 2014).

As the causes of these difficulties, EFL students mostly stated that dictionaries don't have enough information. It is followed by "users' lack of knowledge", "lack of dictionary skills", "unclear layout of the dictionary". Likewise, Barın and Gür (2015) obtained similar results. According to their findings $63.6 \%$ of the students stated "not enough knowledge in the dictionary", 24.5\% "my lack of dictionary knowledge", $21.9 \%$ "my lack of dictionary skills" as the causes of difficulties. The responses of Algerian freshman EFL students to a similar question were as follows: $46 \%$ "the dictionary is not very efficient (information is vague and inadequate)", $44 \%$ "unclear layout of the dictionary (organization of information is unclear), 22\% "my lack of dictionary using skills", 18\% "my lack of familiarity with the dictionary (Hamdi, 2014).

As the language level of EFL students increased, their perspectives to dictionaries changed. They considered dictionaries as easy tools once their language level increased. Besides, the students with lower level of English considered dictionaries as more informative sources compared to the students in other groups. In Barın and Gür's (2015) study, $58.9 \%$ of the students found dictionaries as informative, $41.7 \%$ easy and $28.5 \%$ tedious/boring.

As the language level of EFL students increased, their beliefs changed. Unlike Pre-Intermediate and Intermediate students, a small amount of students in Beginner and Elementary Classes believed that dictionaries were of no use. Only the students in Elementary Class reported that dictionaries contributed to their reading skills. A significant number of students with $61.4 \%$, thought that dictionaries had more than one benefit and contributed to many language skills. In Barın and Gür's (2015) study, 78.8\% of the students pointed out that dictionaries helped them perform better in their studies, $67.5 \%$ of the students reported that dictionaries improved their writing skills, $35.1 \%$ reading skills and $30.5 \%$ speaking skills. A similar result in a study on Polish students 
learning English was obtained. According to the study Polish students believed that dictionaries were "helpful in improving their writing, and that they offered psychological reassurance during the examination" (Lew, 2016).

About three fourth of EFL students were not trained enough on dictionary use. It was only $26.5 \%$ of the students that had trained on using dictionaries until they started university. In Barın and Gür's (2015) study in response to the question "Have you ever been taught to use a dictionary?" $41.1 \%$ of the students answered "yes", $29.8 \%$ answered "a little" and $29.1 \%$ answered "never". This lack of training causes insufficient use of dictionaries in language education or wrong selection of dictionaries. As a matter of fact, the results from all over the world were not any different from those in Turkey. According to Carstens (1995) "results showed that few of them could explain the difference between the basic dictionary types". For instance, $47.5 \%$ of Albanian students who were learning English had not been trained on how to use a dictionary (Koca et al., 2014). Carstens (1995) also states that "even teachers are often unaware of the advantages and disadvantages different dictionary types have with regard to different stages of learning (introductory, intermediate and advanced) and different learning tasks. Many teachers therefore content themselves with the outdated and/or inappropriate dictionaries left by their predecessors". This causes the dictionaries to go beyond the general aim and to stay away the target to be reached. As Bejoint (1989) pointed out the main aim of dictionaries is "to help students help themselves, to help them to learn for themselves from dictionaries... to help them become independent of a teacher... and this is very important in a world that stresses individual training" (qtd. in Carstens, 1995). How is that possible to expect to realize this situation from students who have not been trained on dictionary use and do not have enough skills of dictionary use? For a more efficient language teaching "dictionary-using skills be taught according to a principled strategy and incorporated into language learning programmes" (Carstens, 1995). Similarly, Lew states that "in order to benefit from the achievements of modern lexicography, dictionary users need to be trained how to use the dictionary to solve actual problems and questions" (2011). The findings of a study conducted by Liu (2014) on Chinese EFL students who had not had a training on dictionary use revealed that students did not know when to consult a dictionary while reading and when they consulted a dictionary they applied the meanings mechanically; students often mistranslated the words and phrases when translating and they trusted too much on sentence to sentence translation when writing. According to Liu, as a result of the lack of training on dictionary use, a new kind of language called Chinglish emerged (2014).

\section{Conclusion}

Although university students learning English as a foreign language in Turkey bought dictionaries at an early age, they did not have any training on how to choose a dictionary and how to use them. Therefore, they do not have a strong belief that dictionaries will be beneficial to them during the process of learning a foreign language. However, as students' language level increases and they realize that dictionaries contribute to foreign language learning, a positive attitude towards dictionaries emerges. Besides, the students whose languages skills haven't developed enough cannot determine which dictionary will be more beneficial to their language learning process. As a result, the lack of dictionary using skills causes students to make wrong choices, to be unable to understand the abbreviations used in the dictionaries, to look up only the meaning of words and disregard other useful information, which causes misinterpretation of words and mistranslations. Furthermore, these students refrain from using dictionaries as they consider them difficult tools to use.

Since the students learning English as a foreign language in Turkey have got no training on dictionary use, they cannot determine the right dictionary for them and consequently tend to use bilingual dictionaries (English-Turkish/Turkish-English). Yet, teachers can lead students to other types of dictionaries such as bilingualised ones which give better results both in comprehension and production of new words (Laufer \& Hadar, 1997).

As students' level of language increases and they learn how to use a dictionary, they tend to use dictionary applications downloaded on their mobile phones and give up using print dictionaries. Therefore, appropriate dictionary applications should be developed in order to benefit students' recent dictionary using behaviours. In addition, students should be informed that each dictionary application may not provide accurate and sufficient information or may not be useful for an appropriate language teaching.

Students learning English as a foreign language generally consult dictionaries while studying at home yet these students do not read the front matter guidance notes and consequently they either misuse the dictionaries or spend a lot of time to find the information looked up. This may have a negative effect on students' beliefs to dictionaries. As Carstens (1995) states "resistance to dictionary use is a world-wide tendency, especially among school pupils. It is probably due to the fact that most students lack adequate reference skills and that dictionaries have resultantly frustrated them or let them down". Therefore, new types of dictionaries should be incorporated 
into foreign language learning and teaching environment and dictionary usage skills should be taught systematically like teaching other skills such as reading, writing, speaking and listening.

\section{References}

Abecassis, M. (2007). Is lexicography making progress? On dictionary use and language learners' needs. Lexikos, $17,247-258$.

Al Amin, A. A. S. N., \& Siddiek, A. G. (2015). Investigating students' attitudes towards pedagogical dictionaries: A study of Sudanese English majors. International Journal of Language and Linguistics, 2(1), 91-107.

Atkins, B. T., \& Knowles, F. E. (1990). Interim report on the EURALEX/AILA research project into dictionary use. EURALEX88 PROCEEDINGS, 381-392.

Barın, M., \& Gür, C. (2015). Dictionary culture among students of English: A case study. Atatürk Üniversitesi Sosyal Bilimler Enstitüsü, 19, 145-162.

Baxter, J. (1980). The dictionary and vocabulary behavior: A single word or a handful? TESOL Quarterly, 14(3), 325-336. https://doi.org/10.2307/3586597

Carstens, A. (1995). Language teaching and dictionary use: an overview. Lexikos, 5, 105-116.

Chan, A. Y. W. (2014). How can ESL students make the best use of learners' dictionaries? English Today, 30(3), 33-37. https://doi.org/10.1017/S0266078414000248

Dakun, W. (2001). Should they look it up? The role of dictionaries in language learning. React, 20(1).

Gürcü, C. (2013). Metalexicography: A case study of dictionary culture among students of English (Unpublished master's dissertation). Erzurum: Atatürk Üniversitesi Sosyal Bilimler Enstitüsü.

Hamdi, C. (2014). Drawing the profile of students of English as dictionary users. Revue Sciences Humaines, 41, $57-75$.

Jackson, H., (2002) Lexicography: An introduction. London and New York: Routledge. https://doi.org/10.4324/9780203467282

Kent, D. (2001). Korean university freshmens' dictionary use and perceptions regarding dictionaries. The Korea TESOL Journal, 4(1), 73-92.

Knight, S. (1994). Dictionary use while reading: the effects on comprehension and vocabulary acquisition for students of different verbal abilities. The Modern Language Journal, 78(3), 285-299. https://doi.org/10.1111/j.1540-4781.1994.tb02043.x

Koca, S., Pojani, V., \& Jashari-Cicko, A. (2014). Dictionary use by EFL university students a case-study at Korça $\begin{array}{lllll}\text { University. Mediterranean Journal of Social Sciences, 5(19), } & \text { 74-83. }\end{array}$ https://doi.org/10.5901/mjss.2014.v5n19p74

Laufer, B., \& Hadar, L. (1997). Assessing the effectiveness of monolingual, bilingual and bilingualised dictionaries in the comprehensin and production of new words. The Modern Language Journal, 81, 189-196.

Lew, R. (2011). Studies in dictionary use: Recent developments. International Journal of Lexicography, 24(1), 1-4. https://doi.org/10.1093/ijl/ecq044

Lew, R. (2016). Can a dictionary help you write better? A user study of active bilingual dictionary for Polish learners of English. International Journal of Lexicography, 29(3), 353-366. https://doi.org/10.1093/ij1/ecw024

Liu, L. (2014). The integration of dictionary use strategy training into basic English class. Theory and Practice in Language Studies, 4(10), 2138-2143. https://doi.org/10.4304/tpls.4.10.2138-2143

Nuccorini, S. (1992). Monitoring dictionary use. EURALEX '92 Proceedings (Eds. Hannu Tommola, Krista Varantola, Tarja Salmi-Tolonen, Jurgen Schopp, pp. 89-102). Finland: Tampereen Yliopisto.

Şevik, M. (2017). An investigation of EFL student teachers' dictionary ownership and preferences. Lublin Studies in Modern Languages and Literature, 41(1), 214-232. https://doi.org/10.17951/lsmll.2017.41.1.214

Types of Dictionaries/ (2017, October 1st). In Ciil-ebooks. Retrieved from $\mathrm{http}: / /$ www.ciil-ebooks.net/html/lexico/link5.htm

Vahdany, F., Abdollahzadeh, M., Gholami, S., \& Ghanipoor, M. (2014). A study of the relationship between type of dictionary used and lexical proficiency in writings of Iranian EFL students. Advances in Language and 
Literary Studies, 5(6), 31-38.

$\mathrm{Xu}, \mathrm{X}$. (2010). Study on the effect of dictionary use on second language incidental vocabulary acquisition - an empirical study of college English vocabulary learning strategy. Journal of Language Teaching and Research, 1(4), 519-523. https://doi.org/10.4304/jltr.1.4.519-523

\section{Copyrights}

Copyright for this article is retained by the author(s), with first publication rights granted to the journal.

This is an open-access article distributed under the terms and conditions of the Creative Commons Attribution license (http://creativecommons.org/licenses/by/4.0/). 